\title{
Medidas de mitigación que la población debe empoderarse para combatir el COVID-19
}

\author{
Mitigation measures that the population must \\ be empowered to combat COVID-79 \\ Adela Alba Leonel,* Joaquín Papaqui Hernández,łSamantha Papaqui Alba
}

\section{RESUMEN}

Introducción: La COVID-19 es una enfermedad que está presente y seguirá estándolo, por lo que se han de tomar algunas disposiciones de protección y mitigación a fin de combatirla, en tanto no haya una vacuna o tratamiento específico. El estado ha implementado diferentes medidas de amortiguamiento, las cuales debe aplicar la ciudadanía y, mientras más rápido se pongan en marcha, mejor será el pronóstico de la pandemia. Es necesario empoderar a la población a través de la evidencia de su empleo. Tales providencias son: quedarse en casa, guardar sana distancia, uso de cubreboca, uso de careta, lavado frecuente de manos, uso de gel con alcohol al 70\%, estornudo de etiqueta, no tocarse nariz, ojos y boca, entre otras. Conclusiones: Para que las medidas de atenuación resulten eficaces se requiere que éstas se sigan de forma corresponsable, con el propósito de disminuir la transmisión del virus, evitar la gravedad del trastorno y su impacto en la población, por lo que se tendrían que aplicar todas o casi todas las prevenciones. La pandemia por COVID-19 ha enseñado una nueva manera de vida y de hábitos; el cambio no ha sido fácil, sin embargo, se debe hacer por la salud de todos los habitantes. Por ello la responsabilidad de uno es consigo mismo y hacia otras personas.

Palabras clave: Medidas de mitigación, COVID-19, transmisibilidad, gravedad de enfermedad, impacto en la población.

\begin{abstract}
Introduction: COVID-19 is a disease that will continue to be present, so one must take some protection and mitigation measures to combat it, as long as vaccination and treatment are not fully available worldwide. The state has put forward diverse mitigation measures, which the population must adopt, and the faster they are implemented, the better the prognosis of this pandemic will be. These are: staying at home, social distancing, face mask wearing, frequent hand washing, using gel with 70\% alcohol, abstaining from touching nose, eyes and mouth, courtesy sneeze (on the elbow pit), among others. It is necessary to empower the population through evidencing the benefits of those measures. Conclusions: For such actions to be effective, the public must be co-responsible in order to decrease the transmissibility of this virus, avoid the severity of the disease and its impact on such population. Therefore, all or most measures should be applied. The COVID-19 pandemic has forced on all a new way of life and habits; however, this change has not been easy, it must be embraced for the health of the entire population. One's responsibility is not only to self but also to other people.
\end{abstract}

Keywords: Mitigation measures, COVID-19, transmissibility, disease severity, impact on the population.

\author{
* Doctora en Ciencias de la \\ Salud, campo disciplinar \\ epidemiología. Profesora \\ de Carrera Asociada «C», \\ Universidad Nacional \\ Autónoma de México, \\ Escuela Nacional de \\ Enfermería y Obstetricia. \\ * Ingeniero en Informática \\ y especialista en \\ estadística aplicada. \\ Instituto Mexicano del \\ Seguro Social. \\ $\S$ Estudiante en Saint Luke, \\ Escuela de Medicina, \\ Ciudad de México.
}

Correspondencia: $A A L$, adelaalbaleonel65@gmail. com

ORCID: 0000-0001-

9359-9590

Conflicto de intereses:

Los autores declaran que no tienen.

Citar como: Alba LA, Papaqui HJ, Papaqui AS. Medidas de mitigación que la población debe empoderarse para combatir el COVID-19. Rev CONAMED. 2021; 26(3):

143-148. https://dx.doi. org/10.35366/101679 Financiamiento: Ninguno.

Recibido: 17/07/2020 Aceptado: 27/07/2021 


\section{INTRODUCCIÓN}

La COVID-19, causada por el coronavirus SARSCoV-2, está presente y seguirá estándolo, por lo cual se deben tomar algunos mandatos de protección y mitigación buscando combatirla, en tanto no haya una vacuna y/o un tratamiento específico.

Por lo anterior, se comprende que, a fin de regresar a las actividades diarias, éstas van a ser de forma diferente y el camino que se contempla puede ser largo y complejo; ya que existe la probabilidad de rebrotes o una sucesión de brotes epidémicos; debido a que gran parte de la población no ha estado en contacto o bien no se ha infectado con COVID-19. Por lo tanto, no se cuenta con inmunidad contra este patógeno, y es posible estar expuestos a tal enfermedad en cualquier momento. Por ello, la ciudadanía se ha de empoderar con las medidas de atenuación.

Es importante señalar que en, este momento, la responsabilidad es compartida tanto de los habitantes como del estado en intentar el control de la pandemia.

Todas las políticas que dicte el gobierno en materia de sanidad deben ser claras, precisas y concisas con un lenguaje accesible al público.

Las disposiciones de mitigación dictadas por instituciones de salud son para disminuir la transmisibilidad del virus, incidencia de contagio, proteger a personas vulnerables, evitar la gravedad del padecimiento y su impacto en la población.

\section{DESARROLLO}

El estado ha implementado diferentes medidas de paliación, mismas que necesita aplicar la ciudadanía ya que, mientras más velozmente las ponga en marcha, mejor será el pronóstico de la pandemia de COVID-19; sin embargo, es necesario explicar cuál sería la evidencia de su beneficio, de modo que las adopten más fácilmente.

Quédate en casa

Sana distancia

Uso de cubreboca

Uso de careta

Lavado frecuente de manos
Uso de gel con alcohol al 70\%

Estornudo de etiqueta

No tocarse nariz, ojos y boca

Suspensión de actividades escolares y laborales no críticas

\section{Quédate en casa}

Posee por propósito acotar la transmisión del virus e incidencia de contagio, así como proteger a los individuos vulnerables. En otras palabras, lo que se pretende es disminuir la proporción de casos diarios y sobre todo evitar la muerte, al igual que aminorar el volumen de contagiados hospitalizados.

Esta medida es cardinal, ya que se menciona que, en México y el mundo, hasta 70\% de los ciudadanos podría tener la infección sin manifestar la enfermedad, lo cual hace que haya más transmisibilidad, por eso es muy importante esta forma de mitigación.

Evadir el contacto con otras personas y visitas a las instalaciones de salubridad, (excepto en caso de síntomas graves), permitirá que los servicios funcionen con mayor eficacia. Y de esta manera, se protege de la COVID-19 usted y a otros individuos.

Sólo hay que salir de casa en situaciones de necesidad, como ir al supermercado o a la farmacia por lo imprescindible.

\section{Sana distancia}

Se refiere a que haya un espacio entre un sujeto y otro de uno y medio a dos metros ya que, si una persona con una afección respiratoria, por ejemplo COVID-19, tose o estornuda, expulsa pequeñas gotículas que contienen el germen. Y si está demasiado cerca, se puede inhalar o entrar por ojos, nariz y boca.

Hay que mantener la sana distancia en todos los lugares, como el elevador, restaurante, mercado, banco, si se necesita hacer una fila, etcétera. El distanciamiento social ha mostrado ser insuficiente por sí mismo para proteger al público, por lo que se han planteado otras estrategias de mitigación.

\section{Uso de cubreboca}

El doctor Molina explica que las partículas imperceptibles, denominadas aerosoles (también Ilamadas 
gotas o gotículas humanas), nacientes de la atomización respiratoria, que se producen principalmente al hablar, toser o estornudar, son una vía de transmisión de la enfermedad, por lo que el empleo de tapaboca disminuye la probabilidad de contagio. ${ }^{2}$

La diferencia entre hacer obligatorio o no el uso de máscaras determinó el curso de la pandemia en tres sitios distintos (Wuhan, China; Italia y Nueva York), esta medida redujo significativamente el número de casos. ${ }^{3}$

El uso de cubreboca o barbijo es fundamental en espacios públicos o cerrados. También es muy importante seleccionar cuál es el mejor para mitigar la infección, cómo se debería usar y sobre todo darle la higiene adecuada.

A fin de seleccionar el uso de tapaboca, primero es necesario conocer las características físicas del virus. Igualmente, se ha de tomar en cuenta que el cubreboca cumpla con las características de filtrar el aire que entra a los pulmones y, sobre todo, que permita respirar.

Algunas de las presuntas causas de reticencia ante utilizar el tapaboca son: que incomoda, que genera calor, que no permite respirar. Sin embargo, es relevante mencionar que el cubreboca funciona a modo de una barrera contra los aerosoles expelidos por un infectado al respirar, hablar, toser o estornudar.

El contagio se podría dar incluso al intercambiar palabras con alguien aparentemente sano, asintomático o con presíntomas. Hoy se sabe que todos exhalan de manera constante microgotas que van desde las 60 a las 300 micras, y que la vía de entrada del patógeno es por nariz, boca y ojos.

Las mascarillas más efectivas no sólo son las N95 de uso médico, sino también algunas que son confeccionadas en tres capas con tela de filtros de aspiradora (polipropileno); los materiales de las primeras y las segundas poseen propiedades químicas semejantes. Estos filtros son más accesibles económicamente y el material se puede conseguir de manera fácil para elaborarlos; la primer capa, la más superficial, debería ser de una tela repelente al agua, como el poliéster, se recomienda que cumpla con esta característica ya que no todos los poliésteres son repelentes al agua; la segunda capa es una especie de bolsa donde colocar la tela que ha de tener la función de filtrar (ésta podría ser de líneas o elementos de hilos de algodón en forma de red o «retícula») es muy importante que ésta se pueda cambiar o quitar para lavarse y la tercera capa debe ser suave ya que es la que está en contacto con nariz y boca. De este modo, es posible impedir que alguien más respire esas exhalaciones o que otra persona deje las suyas.

Si uno lo va a comprar, es también imprescindible que cumpla con las características antes descritas, ya que en ocasiones preocupa más la estética y no la protección de la salud. Hoy en día, se encuentra disponible una gran diversidad de cubrebocas, con diferentes materiales, aspectos y estampados. Por lo que antes de adquirir uno habría que ver que cumpla con las tres capas y el tipo de material con el que está elaborado; ya que ciertos modelos ya fueron prohibidos en diversas ciudades de Estados Unidos por el riesgo sanitario que implica que tengan válvula. ${ }^{4}$

Las válvulas están diseñadas con tal de facilitar la respiración, estos cubrebocas limpian el aire entrante, evitan que se empañen lentes, sin embargo, permiten salir las exhalaciones sin filtrarlas, lo que representa un problema, porque si quien lo usa está infectado, este individuo propagará el virus por doquiera que pase. Si se desea acabar con la pandemia se requiere romper el ciclo de contagio.

\section{Usos y cuidados del cubreboca}

Antes de colocar el tapaboca, primero se deben lavar las manos, posteriormente, al colocarlo ha de asegurarse de cubrir desde la parte baja de barbilla hasta el puente de la nariz, y sólo se tendría que manipular por las puntas que van en las orejas o por las ligas de sujeción y, una vez colocado, no se debe toquetear, ya que podría contaminarse con microorganismos que en ocasiones se portan en las palmas. A manera de que el tapaboca cumpla su cometido, se ha de emplear adecuadamente y nunca se debería quitar ni al hablar.

Si el cubreboca es desechable, se debería usary desechar, máximo a las 24 horas, y si éste no es desechable, ha de lavarse diario con agua y jabón; igualmente, cambiar el filtro diario o bien sumergirlo 
en alcohol al 70\% y dejarlo secar por un día, lo que significa que se indica tener dos o tres más de repuesto.

El médico, al estar en contacto con pacientes con COVID-19, necesariamente ha de utilizar tapaboca N95 para su protección y su uso máximo es de cinco horas; la población no debería emplear este tipo de cubreboca y, si lo emplea, tiene que ser en espacios abiertos y desecharlo en 24 horas.

Se impone ser muy cuidadoso con la higiene, así como uno se ha acostumbrado a lavarse las manos con regularidad, también se requiere aprender a desinfectar el cubreboca reusable.

El tapaboca es y necesita ser parte del equipo de protección que se requiere usar ante esta pandemia.

\section{Una nueva cultura de lavado de manos}

El lavado de manos de forma frecuente debe ser con agua y jabón y de esta manera romper la cadena de transmisión del virus.

La técnica consiste en:

Mojarlas con agua.

Adicionar jabón en las palmas.

Frotar las palmas entre sí.

Frotar la palma derecha contra el dorso de la mano izquierda entrelazando los dedos.

Frotar las palmas entre sí con los dedos entrelazados.

Frotar el dorso de los dedos de una mano con la palma de la mano opuesta, agarrándose los dedos. Frotar con movimiento de rotación del pulgar izquierdo, atrapándolo con la palma derecha y viceversa.

Frotar la punta de los dedos de la mano derecha contra la palma izquierda en modo rotatorio y viceversa.

Enjuagar las manos con agua.

Secarlas con toallas desechables.

Con la toalla desechable cerrar la llave o grifo.

En caso de no poderse lavar las manos con agua y jabón, se sugiere usar gel con alcohol al $70 \%$. Generalmente, los geles son capaces de matar muchas bacterias e inactivar algunos virus, al romper las membranas que los protegen, aunque no funciona con todos los tipos de microorganismos.

La mejor medida de mitigación es lavárselas con agua y jabón.

\section{Caretas}

El uso de careta sirve con la idea de evitar expeler y recibir gotas, esta protege ojos, nariz y boca.

La OMS indica que el uso de careta sólo es efectivo para proteger a los trabajadores sanitarios y reducir el riesgo de que los pacientes enfermos diseminen la enfermedad. ${ }^{5}$

Se recomienda su uso en:

- Las personas que revelan síntomas respiratorios como tos, estornudos o dificultad al respirar si busca atención médica, procurando proteger a los que están a su alrededor.

- Los familiares que brindan atención a parientes con síntomas respiratorios.

- Trabajadores de la salud, cuando ingresan a una habitación con pacientes o cuando tratan a un individuo con síntomas respiratorios, de acuerdo con el tipo de atención que se brinda.

Actualmente, los estudios no han demostrado un claro beneficio del uso de mascarillas en sujetos sanos. Algunas investigaciones muestran que las personas pueden infectarse al manipular una mascarilla contaminada o quitársela incorrectamente.

El sólo uso de una máscara facial no garantiza la detención del contagio, por lo que debe combinarse con otras disposiciones de protección personal, por ejemplo la higiene de las manos, mantener la sana distancia y uso de cubreboca.

\section{Estornudo de etiqueta}

Es toser o estornudar en el ángulo interno del brazo, o cubrir nariz y boca con un pañuelo desechable.

Al cubrir la boca y nariz al toser o estornudar se restringe la transmisión del virus. Si estornuda o tose cubriéndose con las palmas podría contaminar los objetos o las personas que toque. 


\section{Evite tocarse los ojos, nariz y boca}

Las manos tocan muchas superficies que pueden estar contaminadas con el germen. $Y$ si se toca los ojos, nariz o boca con ellas contaminadas, es capaz de transmitir el patógeno de la superficie a sí mismo.

Todas estas medidas de amortiguamiento se deben usar principalmente en espacios públicos y cerrados.

\section{No saludar de mano o de abrazo}

Se necesita evitar el contacto físico al saludarse, ya que a través de dar la mano es posible transmitir el virus u otros gérmenes por lo que se recomienda saludar con el codo; con un gesto con la mano e inclinación de la cabeza.

Suspensión de actividades escolares y laborales no críticas, en tanto el semáforo esté en rojo o si se está enfermo, con el propósito de disminuir la transmisión del contagio.

\section{No visitar a personas vulnerables}

Las personas adultas mayores o aquellos con hipertensión arterial, diabetes mellitus, obesidad e inmunodepresión tienen más probabilidad de desarrollar complicaciones ante el coronavirus.

En México, la prevalencia de sobrepeso y obesidad es de 75\%, 9.4\% padece diabetesy $25.5 \%$ padece hipertensión arterial ${ }^{6}$ por lo que la medida de amortiguamiento de «quédate en casa» es importante.

\section{DISCUSIÓN}

La Organización Mundial para la Salud mencionó que la principal vía de contagio de la COVID-19 son las gotas que expulsa una persona cuando habla, tose o estornuda y por eso la importancia de guardar dos metros de distancia, lavado frecuente de manos y uso de cubreboca.?

Antes, hoy y siempre, la prevención y promoción de la salubridad debe ser el eje que permita manejar o gestionar el riesgo, persiguiendo reducir toda enfermedad transmisible. Y el Estado está obligado a desarrollar programas basados en evidencia que contrarresten o mitiguen los riesgos en el público.
Estrategias ${ }^{5}$ para mitigar problemas de salud pública:

- Los individuos deben protegerse con las providencias recomendadas por el estado.

- Las comunidades necesitan ser empoderadas a fin de asegurar que las estrategias sean aplicadas por los individuos y éstas deben adaptarse a su contexto local.

- El gobierno precisa ampliar el sistema de salubridad pública y promover y asegurar que las medidas se cumplan

- Ciertos establecimientos deberían asegurar la continuidad de servicios esenciales (comida o suministros médicos).

\section{CONCLUSIONES}

Para que las prevenciones de mitigación sean eficaces en la disminución de la transmisión del virus, evitar la gravedad de la infección y su impacto en los habitantes, es necesario aplicar todas o casi todas las disposiciones antes expuestas, de forma corresponsable y así se va a reducir la mortalidad e impedir que se rebase la capacidad de los hospitales.

Así mismo, es valioso mencionar que el uso de estas medidas de mitigación no va a eliminar el riesgo por completo, pero sí pueden prevenir o contener sustancialmente la incidencia de casos.

La pandemia por COVID-19 ha enseñado otro modo de vida, nuevos hábitos, como el uso de cubreboca, la sana distancia, el lavado frecuente de manos con una nueva técnica, entre otras. El cambio no ha sido fácil; sin embargo, éste se debe realizar por la salud de toda la población. Por lo que la responsabilidad de uno es consigo mismo y hacia otras personas.

\section{REFERENCIAS}

1. Zhang R, LiY, Zhang AL, Wang Y, Molina MJ. Identifying airborne transmission as the dominant route for the spread of COVID-19. Proc Natl Acad Sci USA. 2020; 117 (26): 14857-14863. doi: 10.1073/pnas.2009637117.

2. Mario Molina dice síal cubreboca; Sheinbaum le hace caso. [Consultado 11 de julio de 2020]. Disponible en: https:// elanden.mx/item-Mario-Molina-dice-si-al-cubrebocaSheinbaum-le-hace-caso202016646 
3. Paramo O, Nuñez M. Pese a lo que se decía, todos deberíamos usar cubreboca. [Consultado 15 julio de 2020] Disponible en: http://uww.unamglobal.unam.mx/?p=87318

4. ¿Por qué están prohibiendo es uso de mascarillas con uso de tecnología de válvula. [Consultado 16 de julio de 2020] Disponible en: https://www.eluniversal.com.mx/techbit/ por-que-estan-prohibiendo-el-uso-de-mascarillas-contecnologia-de-valvula

5. OPS, OMS, Mascarillas faciales durante brotes: quién, cuándo, dónde y cómo usarlas. [Consultado 11 de julio de 2020] Disponible en: https://www.paho.org/hq/index. php?option=com_content\&view=article\&id $=15744$ :facemasks-during-outbreaks-who-when-where-and-how-touse-them\&ltemid=1926\&lang=es

6. Secretaría de Salud. Encuesta Nacional de Salud y Nutrición de Medio Camino, 2016 (ENSANUT MC, 2016). Informe final de resultados 7-151

7. La OMS admite que "es posible" que el coronavirus se contagie por el aire. [Consultado 15 julio 2020] Disponible en: https://covid19comisionunam.unamglobal.com/?p=87331 